\title{
The Calculation Model of Initiation Pressure During Hydraulic Fracturing Process of Perforated Coal Seams
}

\author{
Li Yuwei* and Ai Chi
}

\author{
Key Laboratory of Education Ministry for Enhanced Oil Recovery, Northeast Petroleum University, Daqing, \\ Heilongjiang, China
}

\begin{abstract}
There are lots of cleats, fractures and many other structure weak planes in coal seams, which make the bullet holes and cleats intersecting. During the hydraulic fracturing process in coal seams, fractures will initiate at coal rock body of borehole wall, and cleats or fractures are different from conventional reservoirs. Thus a new model for initiation pressure calculation during coal seams fracturing should be established. Based on the rock mechanics and elasticity mechanics, and also on network distribution characteristics of coal seam cleats and the space position relationships between the intersected bullet holes and cleats, stress distribution around the bullet holes and at the cleats wall were deducted. The model was established in tensile failure condition. The calculated initiation fracture pressure of Well HX-3 was $10.71 \mathrm{MPa}$. The pressure obtained from bottom hole pressure gauge was $11.24 \mathrm{MPa}$. The relative error was $4.72 \%$. The model could be applied for initiation pressure calculation during hydraulic fracturing process in coal seams. The fractures would initiate at the cleats during fracturing.
\end{abstract}

Keywords: Coal seam, perforated completion, hydraulic fracturing, initiation pressure, cleats.

\section{INTRODUCTION}

Hydraulic fracturing is an important technology to ensure the effective development of coalbed methane. The accurate calculation and prediction of initiation pressure are important for the successful implementation of hydraulic fracturing. It has become a research hotspot and difficulty in CBM hydraulic fracturing. Nowadays studies on initiation pressure of sandstone hydraulic fracturing are mainly based on mechanics of elasticity tensile failure criterion, and the relative calculation models are based on the premise of homogeneous formation [1-5]. For the fractured reservoir, Yan Jin [6, 7] took the influence of reservoir fractures on initiation pressure of open hole well into consideration to establish the relative calculation model. Jinzhou Zhao [8-10] established the initiation pressure calculation model of fractured reservoir under the condition of perforated completion, and analyzed the influence of different initiation patterns on initiation pressure. The calculation of initiation pressure in perforated coal seams mainly referred to the existed sandstone reservoir initiation pressure calculation model, or did simulation using finite element program [11], and there had not been a relatively perfect theory to analyze the influence of cleats and fractures on the initiation pressure of coal seams. The paper considers the differences in mechanical properties of face cleats and butt cleats in coal rock body, and establishes calculation model of initiation pressure in perforated coal seams, which can be used to analyze and determine the different initiation patterns and calculate the initiation pressure, and provides a new method for the initiation pressure calculation during hydraulic fracturing process of perforated coal seams.

\footnotetext{
*Address correspondence to this author at the College of Petroleum Engineering, Northeast Petroleum University, Daqing 163318, Heilongjiang province, China; Tel: 0086-459-6503073; E-mail: liyuweibox@126.com
}

\section{PHYSICAL MODEL OF PERFORATED COAL SEAM}

Coal rock is a kind of fractured rock masses in which lots of cleats, fractures and weak planes develop. Among those weak planes, face cleats and butt cleats are better developed and have a high density, and deliver on the space into a three dimensional mesh (as shown in Fig. 1). Face cleats are approximately parallel to level and generally show plate extension with good continuity, the butt cleats develop only between two face cleats, and approximately vertical to level with poor general continuity.

Because of the complexity of the coal matrix fractures network system, the fractures initiation mechanism during hydraulic fracturing is largely different from that in conventional sandstone reservoir. In order to make sense of the fractures initiation mechanism during hydraulic fracturing process in perforated coal seam, physical model has been established as shown in Fig. (2). The two kinds of fractures, face cleats and butt cleats, intersect and combine in distribution. The angle between face cleats and maximum principal stress is A. Due to the approximately vertical cleats development of face cleats and butt cleats, the angle between face cleats and butt cleats is $\mathrm{B}$, namely $90^{\circ}$. The coal rock body is under the effect of maximum and minimum principal stress. Basic assumptions are put forward as follows: i) Coal rock body is isotropic linear elastomer, and interaction of face cleat and butt cleat can be ignored. ii) The face cleat or butt cleat intersects with bullet hole, and the dips of face cleats and butt cleats are both $90^{\circ}$, namely the cleats plane are vertical to the horizon plane passing the axis of bullet hole. iii) Face cleats have the same trend and dip angle, the butt cleats also have the same trend and dip angle. iv) Ignore the influence of cement loop on the cementing strength casing-cement loop and fractures initiation pressure. 
(a) The space reticular delivery of cleats in coal seam

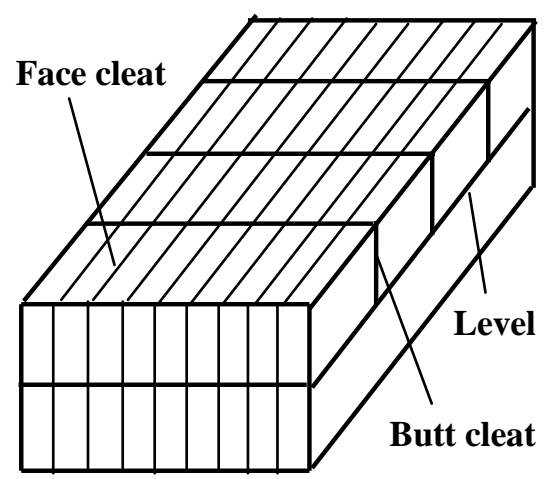

(b) The plane reticular delivery of cleats in coal seam

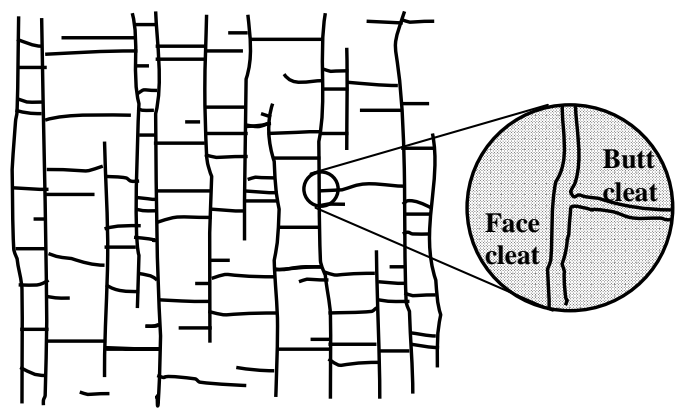

Fig. (1). The simplified model of cleats system in coal seam.

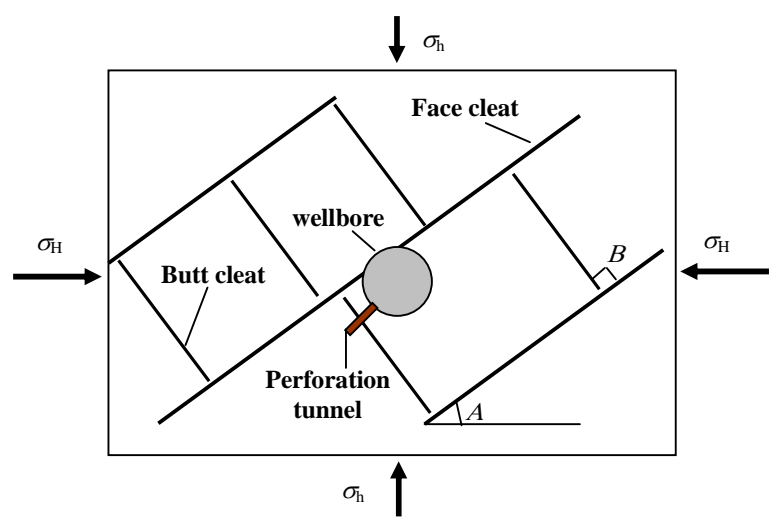

Fig. (2). The physical model of the intersection of cleats and perforation tunnel in perforated coal seam.

\section{BOREHOLE WALL STRESS DISTRIBUTION}

Under the effect of the three principal stresses, maximum principal stress, minimum principal stress and vertical stress, and fracturing fluid pressure in the wellbore, stress concentration will occur in the area near wellbore and perforation tunnel. The stress around the borehole are mainly caused by the in situ stress and the wellbore internal fluid pressure, assuming that tensile stress is negative, compressive stress is positive, it can be obtained that [12]:

$$
\left\{\begin{array}{l}
\sigma_{\mathrm{r}}=\frac{r_{\mathrm{w}}^{2}}{r^{2}} p_{\mathrm{w}}+\frac{1}{2}\left(\sigma_{\mathrm{H}}+\sigma_{\mathrm{h}}\right)\left(1-\frac{r_{\mathrm{w}}^{2}}{r^{2}}\right)+ \\
\frac{1}{2}\left(\sigma_{\mathrm{H}}-\sigma_{\mathrm{h}}\right)\left(1+\frac{3 r_{\mathrm{w}}^{4}}{r^{4}}-\frac{4 r_{\mathrm{w}}^{2}}{r^{2}}\right) \cos 2 \theta \\
\sigma_{\theta}=-\frac{r_{\mathrm{w}}^{2}}{r^{2}} p_{\mathrm{w}}+\frac{1}{2}\left(\sigma_{\mathrm{H}}+\sigma_{\mathrm{h}}\right)\left(1+\frac{r_{\mathrm{w}}^{2}}{r^{2}}\right)- \\
\frac{1}{2}\left(\sigma_{\mathrm{H}}-\sigma_{\mathrm{h}}\right)\left(1+\frac{3 r_{\mathrm{w}}^{4}}{r^{4}}\right) \cos 2 \theta \\
\sigma_{\mathrm{z}}=\sigma_{\mathrm{v}}-2 \mu\left(\sigma_{\mathrm{H}}-\sigma_{\mathrm{h}}\right) \frac{r_{\mathrm{w}}^{2}}{r^{2}} \cos 2 \theta \\
\tau_{\mathrm{r} \theta}=-\frac{1}{2}\left(\sigma_{\mathrm{H}}-\sigma_{\mathrm{h}}\right)\left(1-\frac{3 r_{\mathrm{w}}^{4}}{r^{4}}+\frac{2 r_{\mathrm{w}}^{2}}{r^{2}}\right) \sin 2 \theta \\
\tau_{\theta \mathrm{z}}=\tau_{\mathrm{rz}}=0
\end{array}\right.
$$

where: $\sigma_{\mathrm{r}}$ is the radial stress in borehole area, MPa; $\sigma_{\theta}$ is circumferential stress, MPa; $\sigma_{\mathrm{z}}$ is the vertical stress, $\mathrm{MPa}$; $\tau_{\mathrm{r} \theta}, \tau_{\theta \mathrm{z}}$ and $\tau_{\mathrm{rz}}$ are the shear stress, MPa; $\sigma_{\mathrm{H}}$ is maximum principal stress; $\sigma_{\mathrm{h}}$ is minimum principal stress, MPa; $\sigma_{\mathrm{V}}$ is the overburden stress, $\mathrm{MPa} ; r$ is the wellbore polar radius, $\mathrm{m}$; $r_{\mathrm{w}}$ is the radius of wellbore, $\mathrm{m} ; \mu$ is the Poisson's ratio, dimensionless variable; $p_{\mathrm{w}}$ is the fluid pressure in the wellbore, $\mathrm{MPa}$; $\theta$ is the sinistral polar angle of maximum principal stress in radial direction.

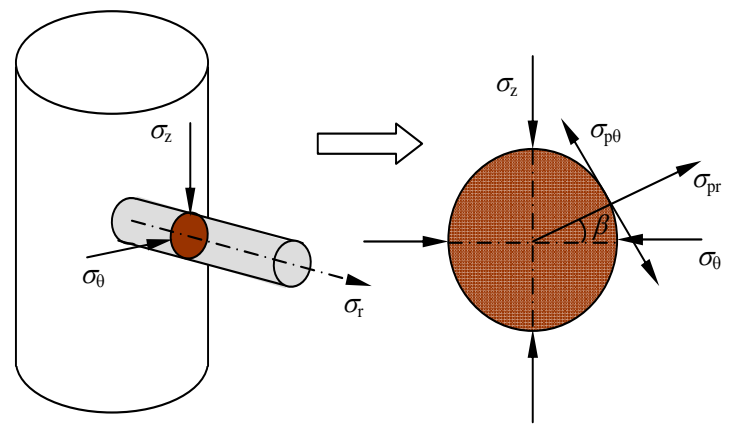

Fig. (3). The diagram of surrounding rock stress of perforation tunnel.

Perforation tunnel can be regarded as a small orthogonal uncased wellbore intersecting with borehole axis, it is shown in Fig. (3), the stress in perforation tunnel is determined by the stress distribution around the wellbore. In axial direction, the tunnel affects borehole radial stress $\sigma_{\mathrm{r}}$, of the area around wellbore, in horizontal direction it affects the circumferential stress $\sigma_{\theta}$, in vertical direction it affects the vertical stress, and it is also under the influence of the shear stress $\tau_{\mathrm{r} \theta}$. Due to the fracturing fluid pressure exerting on the tunnels wall at the same time during the hydraulic fracturing process, and taking the seepage effect of fracturing fluid into consideration, the stress distribution around the perforation tunnels wall can be obtained [9]. 


$$
\begin{aligned}
& \sigma_{\mathrm{pr}}=\frac{\sigma_{\theta}+\sigma_{\mathrm{z}}}{2}\left(1-\frac{r_{\mathrm{p}}^{2}}{L_{\mathrm{p}}^{2}}\right)+\frac{\sigma_{\theta}-\sigma_{\mathrm{z}}}{2} \\
& \left(1+\frac{3 r_{\mathrm{p}}^{4}}{L_{\mathrm{p}}^{4}}-\frac{4 r_{\mathrm{p}}^{2}}{L_{\mathrm{p}}^{2}}\right) \cos 2 \beta+\frac{r_{\mathrm{p}}^{2}}{L_{\mathrm{p}}^{2}} p_{\mathrm{w}} \\
& +\left[\frac{\alpha(1-2 \mu)}{2(1-\mu)}\left(1-\frac{r_{\mathrm{p}}^{2}}{L_{\mathrm{p}}^{2}}\right)-\phi\right]\left(p_{\mathrm{w}}-p_{\mathrm{p}}\right) \\
& \sigma_{\mathrm{p} \theta}=\frac{\sigma_{\theta}+\sigma_{\mathrm{z}}}{2}\left(1+\frac{r_{\mathrm{p}}^{2}}{L_{\mathrm{p}}^{2}}\right)-\frac{\sigma_{\theta}-\sigma_{\mathrm{z}}}{2} \\
& \left(1+\frac{3 r_{\mathrm{p}}^{4}}{L_{\mathrm{p}}^{4}}\right) \cos 2 \beta-\frac{r_{\mathrm{p}}^{2}}{L_{\mathrm{p}}^{2}} p_{\mathrm{w}} \\
& +\left[\frac{\alpha(1-2 \mu)}{2(1-\mu)}\left(1+\frac{r_{\mathrm{p}}^{2}}{L_{\mathrm{p}}^{2}}\right)-\phi\right]\left(p_{\mathrm{w}}-p_{\mathrm{p}}\right) \\
& \sigma_{\mathrm{pz}}=\sigma_{\mathrm{r}}-2 \mu\left(\sigma_{\theta}-\sigma_{\mathrm{z}}\right) \frac{r_{\mathrm{p}}^{2}}{L_{\mathrm{p}}^{2}} \cos 2 \beta+ \\
& {\left[\frac{\alpha(1-2 \mu)}{1-\mu}-\phi\right]\left(p_{\mathrm{w}}-p_{\mathrm{p}}\right)} \\
& \tau_{\mathrm{pz} \beta}=\tau_{\mathrm{r} \theta} \sin \beta\left(1+\frac{r_{\mathrm{p}}^{2}}{L_{\mathrm{p}}^{2}}\right) \\
& \tau_{\mathrm{pr} \beta}=-\frac{\sigma_{\theta}-\sigma_{\mathrm{z}}}{2}\left(1-\frac{3 r_{\mathrm{p}}^{4}}{L_{\mathrm{p}}^{4}}+\frac{2 r_{\mathrm{p}}^{2}}{L_{\mathrm{p}}^{2}}\right) \sin 2 \beta \\
& \tau_{\mathrm{prz}}=-\tau_{\mathrm{r} \theta} \cos \beta\left(1-\frac{r_{\mathrm{p}}^{2}}{L_{\mathrm{p}}^{2}}\right)
\end{aligned}
$$

where: $\sigma_{\mathrm{pr}}$ is the radial stress around the perforation tunnels, $\mathrm{MPa} ; \sigma_{\mathrm{p} \beta}$ is the circumferential stress around the perforation tunnels, MPa; $\sigma_{\mathrm{pz}}$ is the vertical stress around the perforation tunnels, MPa; $\tau_{\mathrm{pr} \beta}, \tau_{\mathrm{prz}}$ and $\tau_{\mathrm{pz} \beta}$ are the shear stress, MPa; $\alpha$ is the Biot factor; $\Phi$ is the porosity, dimensionless variable; $p_{\mathrm{p}}$ is the pore pressure, $\mathrm{MPa} ; r_{\mathrm{p}}$ is the radius of perforation tunnel, $\mathrm{m} ; L_{\mathrm{p}}$ is the distance from perforation tunnel axis, $\mathrm{m}$; $\beta$ is the sinistral polar angle of circumferential stress in radial direction of perforation tunnel.

When $L_{\mathrm{p}}=r_{\mathrm{p}}$, the stress on perforation tunnels wall is:

$$
\left\{\begin{array}{l}
\sigma_{\mathrm{pr}}=p_{\mathrm{w}}-\phi\left(p_{\mathrm{w}}-p_{\mathrm{p}}\right) \\
\sigma_{\mathrm{p} \beta}=\sigma_{\theta}+\sigma_{\mathrm{z}}-2\left(\sigma_{\theta}-\sigma_{\mathrm{z}}\right) \cos 2 \beta-p_{\mathrm{w}} \\
+\left[\frac{\alpha(1-2 \mu)}{1-\mu}-\phi\right]\left(p_{\mathrm{w}}-p_{\mathrm{p}}\right) \\
\sigma_{\mathrm{pz}}=\sigma_{\mathrm{r}}-2 \mu\left(\sigma_{\theta}-\sigma_{\mathrm{z}}\right) \cos 2 \beta-p_{\mathrm{w}} \\
+\left[\frac{\alpha(1-2 \mu)}{1-\mu}-\phi\right]\left(p_{\mathrm{w}}-p_{\mathrm{p}}\right) \\
\tau_{\mathrm{pz} \beta}=2 \tau_{\mathrm{r} \theta} \sin \beta \\
\tau_{\mathrm{pr} \beta}=\tau_{\mathrm{prz}}=0
\end{array}\right.
$$

\section{THE CALCULATION MODEL OF FRACTURES INITIATION PRESSURE}

When the perforation tunnels do not intersect with cleats, fractures will initiate from coal rock body. When the perforation tunnels intersect with face cleats and butt cleats, so the fractures initiation patterns will be different, it may be from coal rock body crack, along face cleats or butt cleats respectively. As a result, the initiation pressure calculation model under different initiation patterns should be deducted respectively to analyze the initiation pressure of coalbed methane wells under different conditions.

\subsection{The Analysis of the Initiation Pressure of Coal Rock Body}

When the hydraulic fracture initiates along the perforation tunnel walls, the initiation point should be at the tunnel wall where the largest tensile stress exists. The largest tensile stress of any point can be calculated through combined stress theory in plasto elasticity, and its calculation formula is:

$$
\sigma(\beta)=\frac{1}{2}\left[\left(\sigma_{\mathrm{pz}}+\sigma_{\mathrm{p} \beta}\right)-\sqrt{\left(\sigma_{\mathrm{pz}}-\sigma_{\mathrm{p} \beta}\right)^{2}+4 \tau_{\mathrm{pz} \beta}^{2}}\right]
$$

The maximum tensile stress $\sigma(\beta)$ of perforation tunnel wall is the function to $\beta$, to derivate formula (4) the value of extreme point $\sigma(\beta)$ can be obtained. Suppose after derivate formula (4), the initiation azimuth of perforation tunnel wall of coal rock body is $\beta_{0}$, the corresponding maximum tensile stress is $\sigma\left(\beta_{0}\right)$. According to tensile fracture criterion based on elastic mechanics, apply effective stress to calculate the initiation conditions of the coal rock body of perforation tunnel wall:

$\sigma\left(\beta_{0}\right)-\alpha p_{\mathrm{p}} \leq-\sigma_{\mathrm{t}}$

where: $\sigma_{\mathrm{t}}$ is the tensile strength of coal rock, MPa.

\subsection{The Calculation of Initiation Along Cleats}

When the perforation tunnels intersect with face cleats and butt cleats, the hydraulic fracture will initiate from face cleat or butt cleat in different patterns. The perforation tunnel intersects with face cleats, and the physical model can be set up as shown in Fig. (4). To any point $(r, \varphi)$ on face cleat, its normal stress and shear stress can be indicated as:

$$
\left\{\begin{array}{l}
\sigma(r, \varphi)=\frac{\left(\sigma_{\mathrm{x}}+\sigma_{\mathrm{y}}\right)}{2}-\frac{\left(\sigma_{\mathrm{x}}-\sigma_{\mathrm{y}}\right)}{2} \cos 2 A+\tau_{\mathrm{xy}} \sin 2 A \\
\tau(r, \varphi)=\frac{\left(\sigma_{\mathrm{x}}-\sigma_{\mathrm{y}}\right)}{2} \sin 2 A+\tau_{\mathrm{xy}} \cos 2 A
\end{array}\right.
$$

where: $\sigma(r, \varphi)$ and $\tau(r, \varphi)$ are the normal stress and shear stress of any point $(r, \varphi)$ on face cleats respectively, $\mathrm{MPa} ; \sigma_{\mathrm{x}}$ and $\sigma_{\mathrm{y}}$ are the principal tress on $x$ and $y$ direction of wellbore vertical section respectively, MPa.

The definition process of $\sigma_{\mathrm{x}}$ and $\sigma_{\mathrm{y}}$ can be depicted as follows: First determine the stress distribution around perforation tunnel in polar coordinates through formula (2) and (3), decomposition and the force on the coordinate transformation for $x, y$ plane. Especially when the $x y$ plane is on the section which goes through perforation axial line, the 
stress distribution that has been transformed can be expressed as follow.

$$
\left\{\begin{array}{l}
\sigma_{\mathrm{x}}=\sigma_{\mathrm{pr}} \cos ^{2}\left(A+\left|C-A-\frac{\pi}{2}\right|\right)+\sigma_{\mathrm{pz}} \sin ^{2}\left(A+\left|C-A-\frac{\pi}{2}\right|\right) \\
-\tau_{\mathrm{prz}} \sin \left[2\left(A+\left|C-A-\frac{\pi}{2}\right|\right)\right] \\
\sigma_{\mathrm{y}}=\sigma_{\mathrm{pz}} \cos ^{2}\left(A+\left|C-A-\frac{\pi}{2}\right|\right)+ \\
\sigma_{\mathrm{pr}} \sin ^{2}\left(A+\left|C-A-\frac{\pi}{2}\right|\right)+ \\
\tau_{\mathrm{prz}} \sin ^{2}\left[2\left(A+\left|C-A-\frac{\pi}{2}\right|\right)\right] \\
\tau_{\mathrm{xy}}=\frac{1}{2}\left(\sigma_{\mathrm{pr}}-\sigma_{\mathrm{pz}}\right) \sin \left[2\left(A+\left|C-A-\frac{\pi}{2}\right|\right)\right]+ \\
\tau_{\mathrm{prz}} \cos \left[2\left(A+\left|C-A-\frac{\pi}{2}\right|\right)\right]
\end{array}\right.
$$

During the hydraulic fracturing process, the fluid pressure in the tunnel continually increasing, when the fluid pressure at the intersection point $b_{A}$ or $b_{B}$ of face cleat and tunnel wall is larger than the normal stress exerted on face cleat, the tensile failure will take place.

$$
p_{\mathrm{w}}-\alpha p_{\mathrm{p}} \geq \sigma
$$

Through the tensile failure pattern of face cleats the initiation pressure when the perforation tunnel intersects with face cleat can be calculated, while the calculation of the initiation pressure when the perforation tunnel intersect with butt cleat is the same.

\subsection{The Calculation of Initiation Pressure}

To the perforated CBM Wells, its initiation pattern and pressure depend on the initiation pressure level under different initiation patterns. Supposing that the initiation pressure is $p_{\mathrm{bz}}$, when the failure origins from the coal rock body, origins from the face cleats is $p_{\mathrm{mz}}$, and origins from the butt cleats is $p_{\mathrm{dz}}$. So during hydraulic fracturing process, the actual initiation pressure should be the minimum value of the three, and the failure pattern is the relative initiative pattern, the initiation pressure can be represented as:

$p_{\mathrm{f}}=\min \left\{p_{\mathrm{bz}}, p_{\mathrm{mz}}, p_{\mathrm{dz}}\right\}$

where: $p_{\mathrm{f}}$ is the initiation pressure of perforated CBM Wells, MPa.

\section{EXAMPLE CALCULATION}

CBM Well HX-3 in the southern coal seam of Hegang mining area, the horizontal maximum principal stress is $12.59 \mathrm{MPa}$, the direction is $72.32^{\circ}$ north by east, the horizontal minimum principal stress is $10.64 \mathrm{MPa}$, the overburden stress is $12.96 \mathrm{MPa}$, the formation pore pressure is $8.81 \mathrm{MPa}$, the porosity is 0.08 , the effective stress coefficient is 0.9 , the borehole radius is $0.1 \mathrm{~m}$, the perforation tunnel's diameter is $0.01 \mathrm{~m}$. Logging and coring data show that the face cleats' strike approximate $64^{\circ}$ north by east, the dip of face cleats and butt cleats is larger, among $82^{\circ} \sim 90^{\circ}$, through indoor experiments, the coal rock mechanics parameters are as follows: Poisson's ratio is 0.33 , elastic modulus is $3800 \mathrm{MPa}$, tensile strength of coal rock body is $0.6 \mathrm{MPa}$.

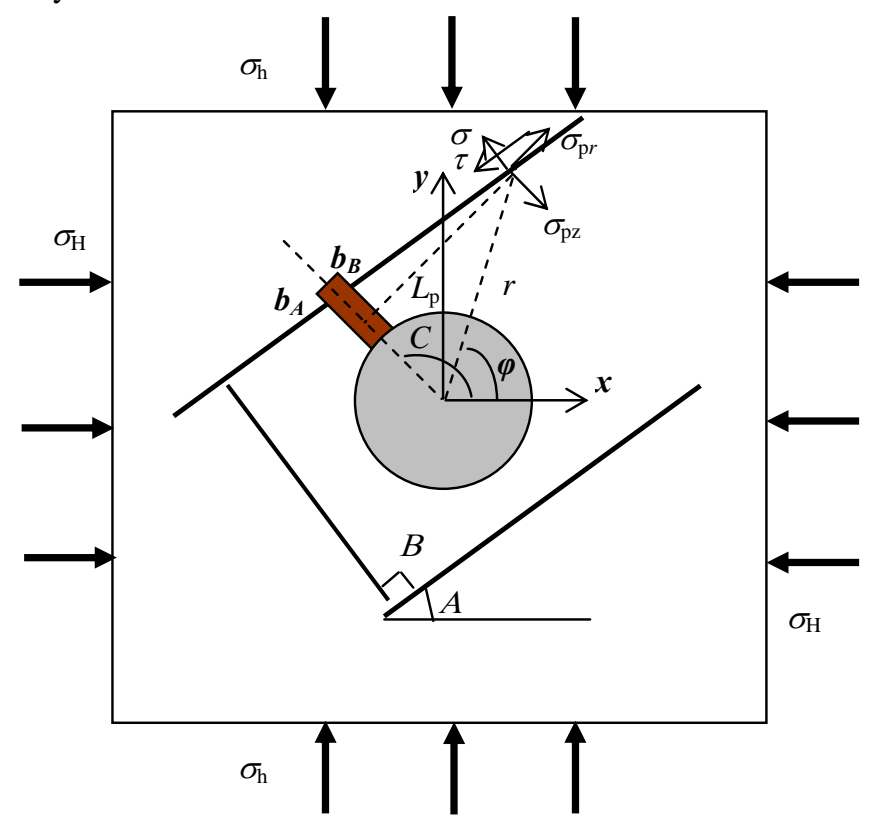

Fig. (4). The stress distribution of borehole wall when perforation tunnels intersect with face cleats.

Apply the model referring in this paper to calculate three kinds of initiation pressure of Well $\mathrm{HX}-3$. The rock body initiation pressure is $14.23 \mathrm{MPa}$, face cleats initiation pressure is $10.71 \mathrm{MPa}$, butt cleats initiation pressure is 48.83 $\mathrm{MPa}$, so for this well fracture initiation origins from face cleats, and initiation pressure is $10.71 \mathrm{MPa}$. Actual fracturing downhole pressure gauge measurement results as shown in Fig. (5), it shows that the fracture initiation pressure is $11.24 \mathrm{MPa}$, which is approximate to the calculation value $10.71 \mathrm{MPa}$, the relative error is $4.72 \%$, within the scope of permissible error value in engineering application. Through the comparisons of actual fracture initiation pressure and the calculated result, it indicates that the calculated result is consistent with the actual situation and the model established in this paper can accurately calculate the initiation pressure during hydraulic fracturing process of perforated coal seams, and has good applicability.

\section{CONCLUSIONS}

1. Taking delivery network distribution characteristics of coal seam cleats and the intersection space position relations between perforation tunnels and cleats into consideration, and basing on the stress relationships at the wall of perforation tunnel and cleat, the calculation model of tensile initiation pressure in perforated coal seam cleats had been established.

2. Example calculation showed that the established initiation pressure calculation mode had high accuracy, and the calculation results were in good agreement with the test results. At the same time, it also proved that initiation could origin from the cleats during the hydraulic fracturing process of coal seam, 
(a) The well head fracturing curve of Well HX-3

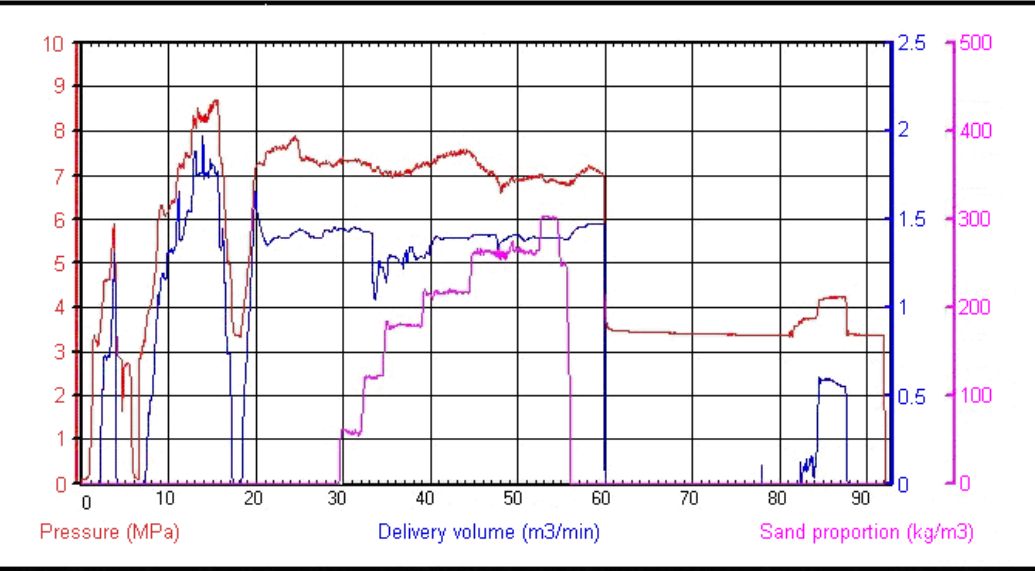

(b) The draw down bottom pressure curve during fracturing process of Well HX-3

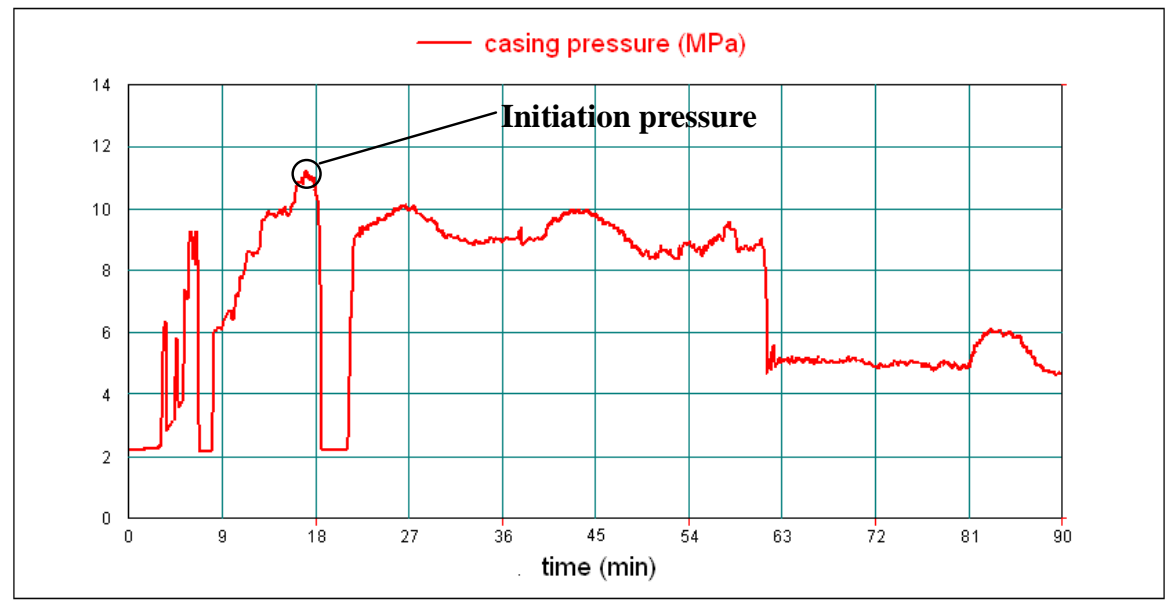

Fig. (5). The measurements of well head and bottom pressure of Well HX-3.

and the value of initiation pressure was obviously lower than that of coal rock body.

\section{NOMENCLATURE}

$\sigma_{\mathrm{r}}$ is the radial stress in borehole area, $\mathrm{MPa}$;

$\sigma_{\theta}$ is circumferential stress, MPa;

$\sigma_{\mathrm{z}}$ is the vertical stress, $\mathrm{MPa}$;

$\tau_{\mathrm{r} \theta}, \tau_{\theta \mathrm{z}}$ and $\tau_{\mathrm{rz}}$ are the shear stress, MPa;

$\sigma_{\mathrm{H}}$ is maximum principal stress;

$\sigma_{\mathrm{h}}$ is minimum principal stress, $\mathrm{MPa}$;

$\sigma_{\mathrm{V}}$ is the overburden stress, $\mathrm{MPa}$;

$r$ is the wellbore polar radius, $\mathrm{m}$;

$r_{\mathrm{w}}$ is the radius of wellbore, $\mathrm{m}$;

$\mu$ is the Poisson's ratio, dimensionless variable;

$p_{\mathrm{w}}$ is the fluid pressure in the wellbore, $\mathrm{MPa}$;

$\theta$ is the sinistral polar angle of maximum principal stress in radial direction;

$\sigma_{\mathrm{pr}}$ is the radial stress around the perforation tunnels, $\mathrm{MPa}$;

$\sigma_{\mathrm{p} \beta}$ is the circumferential stress around the perforation tunnels, MPa; $\sigma_{\mathrm{pz}}$ is the vertical stress around the perforation tunnels, MPa; $\tau_{\mathrm{pr} \beta}, \tau_{\mathrm{prz}}$ and $\tau_{\mathrm{pz} \beta}$ are the shear stress, MPa;

$\alpha$ is the Biot factor;

$\Phi$ is the porosity, dimensionless variable;

$p_{\mathrm{p}}$ is the pore pressure, $\mathrm{MPa}$;

$r_{\mathrm{p}}$ is the radius of perforation tunnel, $\mathrm{m}$;

$L_{\mathrm{p}}$ is the distance from perforation tunnel axis, $\mathrm{m}$;

$\beta$ is the sinistral polar angle of circumferential stress in radial direction of perforation tunnel;

$\sigma_{\mathrm{t}}$ is the tensile strength of coal rock, $\mathrm{MPa}$;

$\sigma(r, \varphi)$ and $\tau(r, \varphi)$ are the normal stress and shear stress of any point $(r, \varphi)$ on face cleats respectively, MPa;

$\sigma_{\mathrm{x}}$ and $\sigma_{\mathrm{y}}$ are the principal tress on $x$ and $y$ direction of wellbore vertical section respectively, $\mathrm{MPa}$;

$p_{\text {bz }}$, is the initiation pressure when the failure origins from the coal rock body, $\mathrm{MPa}$;

$p_{\mathrm{mz}}$ is the initiation pressure when the failure origins from the face cleats, $\mathrm{MPa}$;

$p_{\mathrm{dz}}$ is the initiation pressure when the failure origins from the butt cleats, $\mathrm{MPa}$; 
$p_{\mathrm{f}}$ is the initiation pressure of perforated CBM Wells, MPa.

\section{CONFLICT OF INTEREST}

The authors confirm that this article content has no conflicts of interest.

\section{ACKNOWLEDGEMENTS}

The support of National Natural Science Fund of China (No.51274067) is gratefully acknowledged.

\section{REFERENCES}

[1] Haimson, B.; Fairhurst, C. Initiation and extension of hydraulic fractures in rocks. SPE Journal, 1967, 7(3), 310-318.

[2] Yew, C.H.; Li, Y. Fracturing of a deviated well. SPE 16930, 1987.

[3] Hossain, M.M.; Rahman, M.K. Hydraulic fracture initiation and propagation: roles of wellbore trajectory, perforation and stress regimes. J.Pet.Sci.Eng, 2000, 27(3), 129-149.

[4] Luo, Tianyu; Guo, Jianchun; Zhao, Jinzhou; Wang, Jiahuai; Pan, Jingjun. Study on fracture initiation pressure and fracture starting point in deviated wellbore with perforations. Acta Petrol. Sin., 2007, 28(1), 139-142.
[5] Fallahzadeh, S.H.; Shadizadeh, S.R.; Pourafshary, P. Dealing with the challenges of hydraulic fracture initiation in deviated-cased perforated boreholes. 2010.

[6] Jin, Yan; Zhang, Xudong; Chen, Mian. Initiation pressure models for hydraulic fracturing of vertical wells in naturally fractured formation. Acta Petrol. Sin., 2005, 26(6), 113-124.

[7] Jin, Yan; Chen, Mian; Zhang, Xudong. Hydraulic fracturing Initiation pressure models for directional wells in naturally fractured formation. Acta Petrol. Sin., 2006, 27(5), 124-126.

[8] Zhao, Jinzhou; Ren, Lan; Hu, Yongquan; Wang, Lei. A calculation model of breakdown pressure for perforated wells in fractured formations. Acta Petrol. Sin., 2012, 33(5), 841-845.

[9] Zhao, Jinzhou; Ren, Lan; Hu, Yongquan; Li, Nan. Hydraulic fracture tensile initiation pressure analysis for fractured formations. Chinese J. Rock Mech. Eng., 2013, 32(Supp.1), 2855-2862.

[10] Ren, Lan; Zhao, Jinzhou; Hu, Yongquan; Wang, Lei. Tensile initiation characteristics analysis of hydraulic fracture in perforated well of fractured formations. J. Central South Uni. (Sci. Technol.), 2013, 44(2), 707-713.

[11] Tang, Shuheng; Zhu, Baocun; Yan, Zhifeng. Effect of crustal stress on hydraulic fracturing in coalbed methane wells. J. China Coal Soc., 2011, 36(1), 65-69.

[12] Chen, Mian; Jin, Yan; Zhang, Guangqing. Rock mechanics of petroleum engineering. Science Press: Beijing : 2008. 